\title{
Utilização do Farelo de Castanha de Caju na Terminação de Ovinos em Confinamento ${ }^{1,2}$
}

\author{
Marcelo de Magalhães Rodrigues ${ }^{3}$, José Neuman Miranda Neiva ${ }^{4}$, Vânia Rodrigues de Vascon- \\ $\operatorname{celos}^{5}$, Raimundo Nonato Braga Lôbo ${ }^{6}$, José Carlos Machado Pimentel ${ }^{7}$, Arlindo de Alencar \\ Araripe Noronha Moura ${ }^{4}$
}

\begin{abstract}
RESUMO - O trabalho foi conduzido com o objetivo de avaliar a utilização de concentrados contendo farelo de castanha de caju (FCC) na alimentação de ovinos mantidos em confinamento. Foram testados quatro tipos de concentrados isoprotéicos contendo 0,12 , 24 e $36 \%$ de FCC, tendo o concentrado participado com 30\% da matéria seca (MS) da dieta total. Foram utilizados 32 ovinos sem raça definida (SRD), machos e fêmeas, em esquema fatorial 4 x 2 (quatro níveis de inclusão de FCC e dois sexos) e quatro repetições. Foram avaliados ganho de peso e conversão alimentar, bem como os consumos de matéria seca (CMS), proteína bruta (CPB), extrato etéreo (CEE) e fibra em detergente neutro (CFDN). Estas variáveis foram analisadas conforme o consumo em g/animal/dia, \% do peso vivo (PV) e $\mathrm{g} / \mathrm{UTM}\left(\mathrm{PV}^{0,75}\right)$, tendo sido feita a análise de variância com teste de médias e estudo de regressão. Foram observadas diferenças no CMS, CPB e CEE de animais alimentados com dietas com 0 e 36\% de FCC, com tendência de diminuição dos consumos de MS, PB e FDN, à medida que se aumentou o FCC na dieta. $\mathrm{O}$ consumo de EE elevou-se com a adição $\mathrm{FCC}$ às dietas. $\mathrm{O}$ ganho de peso e a conversão alimentar foram semelhantes para as quatro dietas fornecidas. Portanto, o FCC deve ser utilizado com um nível de inclusão de $24 \%$ do concentrado, não ultrapassando $6 \%$ de lipídios na dieta total.
\end{abstract}

Palavras-chave: confinamento, farelo de castanha de caju, lipídios, ovinos

\section{Levels of Cashew Nuts Meal in Diets for Feedlot Sheep}

\begin{abstract}
A study was conducted to evaluate the use of cashew nuts meal (CNM) in diets for sheep, raised in feedlot. Thirty two crossbred animals received concentrates with the same amount of crude protein, but four different levels of CNM ( $0,12,24$ and $36 \%$ ). A factorial 4 x 2 was used, with four levels of CNM and 2 sexes, with four repetitions. Daily weight gain and feed conversion as well as intake of dry matter (DM), crude protein (CP), ether extract (EE), neutral detergent fiber(NDF) and ashes were determined by analysis of variance, Duncan statistical test and regression analysis. Intake was estimated as g/animal/day, percentage of body weight $(\% \mathrm{BW})$ and $\mathrm{g} / \mathrm{BW}^{0.75}$. There were differences in intake of $\mathrm{DM}, \mathrm{CP}$ and $\mathrm{EE}$ when animals were fed concentrates with 0 and $36 \%$ of $\mathrm{CNM}$. Also, intake of DM, CP and NDF tended to decrease as the levels of CNM increased in the diet. EE intake increased according to the different CNM levels. The type of diet did not significantly affect either weight gain or feed conversion. Therefore, cashew nut meal can be included up to $24 \%$ in the concentrate, but the total diets should not have more than $6 \%$ of fat.
\end{abstract}

Key Words: cashew nut meal, feedlot, lipids, sheep

\section{Introdução}

A ovinocultura é atividade tradicional do Nordeste brasileiro, sendo caracterizada por rebanhos de animais sem raça definida (SRD), com baixo potencial genético e criados de forma extensiva, apresentando, dessa forma, baixos índices de produtividade. A alimentação dos animais é um dos fatores que mais influencia a manutenção deste quadro na região, que sofre longos períodos de estiagem e falta de alimentos.
O confinamento é uma das alternativas encontradas para minimizar este problema, sendo a utilização de subprodutos das indústrias locais uma das várias alternativas encontradas para a mudança da atual situação.

$\mathrm{O}$ farelo de castanha de caju (Anacardium occidentale), oriundo das castanhas impróprias para o consumo humano, vem sendo utilizado para formulação de ração animal, não possuindo, entretanto, dados comprovando a sua eficiência na melhoria da produtividade animal.

\footnotetext{
${ }^{1}$ Projeto financiado pela Fundação Cearense de Amparo ao Desenvolvimento Científico e Tecnológico-FUNCAP.

2 Trabalho extraído da dissertação de Mestrado do primeiro autor.

3 Mestre em Zootecnia, Técnico da PURINA.

4 Professor do Depto de Zootecnia da Universidade Federal do Ceará. E.mail: zeneuman@ufc.br Endereço para correspondência: Av. Mister Hull, SN, Caixa Postal 12168, Fortaleza-CE, CEP: 60970-355.

${ }^{5}$ Professora da Universidade Federal do Piauí. E.mail: vania@ufpi.br

${ }^{6}$ Pesquisador da Embrapa-Caprinos. E.mail: lobo@cnpc.embrapa.br

7 Pesquisador da Embrapa-Agroindústria Tropical. E.mail: machado@cnpat.embrapa.br
} 
No Ceará, a agroindústria do caju ocupa lugar de destaque no contexto econômico e social, sendo o Estado responsável por 57\% da safra de 1991/1992, segundo Pimentel (1992). Segundo a Embrapa (1991), o farelo da castanha de caju (FCC) apresenta 93,27\% de matéria seca (MS), $22,15 \%$ de proteína bruta (PB), 35,97\% de extrato etéreo (EE), 6,24\% de fibra bruta (FB) e 3,09\% de matéria mineral.

De acordo com Palmquist (1989), a crescente demanda energética tem sido tradicionalmente atendida pelo aumento da participação de alimentos concentrados na dieta, sendo utilizadas altas quantidades de carboidratos facilmente fermentáveis, os quais podem ocasionar vários problemas. Segundo este autor, a vantagem da utilização de lipídios em dietas deve-se ao incremento da densidade calórica da dieta, em razão de seu elevado valor energético (aproximadamente $6 \mathrm{Mcal} \mathrm{El} / \mathrm{kg} \mathrm{MS}$ ), vantagem que pode ser explorada de várias maneiras, além de permitir aumento no consumo de energia e balanço mais adequado entre carboidratos estruturais e não-estruturais para a otimização do consumo de fibra e energia digestível.

Emery \& Herdt (1991) citaram que, quando se utilizam lipídios na alimentação de vacas leiteiras, o consumo de MS deve ser monitorado, pois os lipídios tendem a diminuir o consumo nestes animais. Dados semelhantes foram encontrados por Coopock et al. (1985), trabalhando com diferentes níveis de caroço de algodão para vacas em lactação. Entretanto, Grummer et al. (1993) não encontraram diminuição no consumo de MS, PB e matéria orgânica (MO) de animais alimentados com sebo nas proporções de $0,1,2$ e $3 \%$ na dieta total. Estes dados estão em concordância com os descritos por Villela et al. (1996) e Rabello et al. (1996), os quais não encontraram diferenças no consumo de bovinos alimentados com caroço de algodão e soja em grão, respectivamente.

Segundo Palmquist (1989), é desejável que se atinjam níveis de 5 a $6 \%$ de lipídeos na dieta, podendo ser utilizados aproximadamente 3 gramas de ácidos graxos por kg de peso vivo animal por dia.

Em relação ao desempenho animal, Carvalho et al (1995) observaram ganhos de 41,17 a 80,02 g/animal/ dia em ovinos alimentados com capim-elefante e farelo de soja. Já Bett et al. (1999) citam ganhos médios de peso variando de 194 a $219 \mathrm{~g} / \mathrm{animal} / \mathrm{dia}$, utilizando animais alimentados com feno de aveia e grão de canola, entretanto estes autores utilizaram ovinos de raças altamente especializadas para corte.

Em relação à conversão alimentar, Ciríaco (1983) observou valor médio de 13,6 g em ovinos da raça Morada Nova da variedade branca alimentados com feno de cunhã (Clitorea ternatea) e concentrado contendo farelo de soja. Já Oliveira et al. (1986) observaram valor médio para conversão alimentar de 12,12 , trabalhando com animais da raça Morada Nova. Os mesmos autores encontraram valor de 11,86 para animais da raça Santa Inês alimentados com feno de cunhã e concentrado com diferentes níveis de farelo de soja. Camurça et al. (2002) obtiveram valor médio para conversão alimentar de 10,15, trabalhando com animais da raça Santa Inês alimentados com diferentes dietas à base de fenos de gramíneas.

Dessa forma, este trabalho foi conduzido com os objetivos de avaliar o consumo de matéria seca, proteína bruta, fibra em detergente neutro e extrato etéreo, bem como o ganho de peso e a conversão alimentar de ovinos em confinamento e alimentados com farelo de castanha de caju (Anacardium occidentale).

\section{Material e Métodos}

O experimento foi conduzido no Núcleo de Pesquisas em Forragicultura do Departamento de Zootecnia da Universidade Federal do Ceará, no município de Fortaleza, o qual está situado na área litorânea, a $15,49 \mathrm{~m}$ de altitude, $3^{\circ} 43^{\prime} 02^{\prime \prime}$ ' de latitude Sul e $38^{\circ} 32^{\prime} 35^{\prime}$ ' de longitude Oeste. O clima característico é tropical chuvoso, apresentando chuvas predominantemente durante o outono. A precipitação média é de 1378,3 mm e a umidade relativa do ar, de $77 \%$.

Foram utilizados 32 ovinos deslanados SRD (Sem Raça Definida), machos e fêmeas, com idades variando de 8 a 12 meses, com peso vivo médio de $26,5 \mathrm{~kg}$, distribuídos em um esquema fatorial $4 \times 2$ (quatro níveis de inclusão de farelo de castanha de caju (FCC) e dois sexos), com quatro repetições. Foram elaborados e testados quatro tipos de concentrados isoprotéicos contendo $0,12,24$ e 36\% de inclusão de FCC, sendo a dieta fornecida duas vezes ao dia, às 7 e $14 \mathrm{~h}$. Os dados referentes à composição centesimal das rações experimentais e a composição químico bromatológica do feno de capim-elefante, do farelo de castanha de caju e das rações concentradas estão nas Tabelas 1 e 2 .

A dieta total foi composta de $70 \%$ de volumoso, sendo utilizado o feno de capim-elefante e $30 \%$ de ração concentrada. $\mathrm{O}$ feno de capim-elefante foi produzido na Fazenda Experimental Vale do Curú, em Pentecoste, Ceará, sendo o capim cortado com 50-60 dias de idade.

O período experimental compreendeu 56 dias,

R. Bras. Zootec., v.32, n.1, p.240-248, 2003 
Tabela 1 - Composição centesimal das rações experimentais

Table 1 - Centesimal composition of the experimental diets

\begin{tabular}{|c|c|c|c|c|}
\hline $\begin{array}{l}\text { Ingredientes } \\
\text { Ingredients }\end{array}$ & $\begin{array}{l}0 \% \mathrm{FCC}^{1} \\
0 \% C N M\end{array}$ & $\begin{array}{l}12 \% \mathrm{FCC} \\
12 \% \text { CNM }\end{array}$ & $\begin{array}{l}24 \% \mathrm{FCC} \\
24 \% C N M\end{array}$ & $\begin{array}{l}36 \% \mathrm{FCC} \\
36 \% C N M\end{array}$ \\
\hline Milho & 59,76 & 51,59 & 44,03 & 36,48 \\
\hline $\begin{array}{l}\text { Corn } \\
\text { Farelo de soja } \\
\text { Soybean meal }\end{array}$ & 34,14 & 30,30 & 25,87 & 21,4 \\
\hline $\begin{array}{l}\text { Farelo de castanha } \\
\text { Cashew nuts meal }\end{array}$ & 0,0 & 12,0 & 24,0 & 36,0 \\
\hline $\begin{array}{l}\text { Premix mineral } \\
\text { Mineral premix }\end{array}$ & 1,6 & 1,6 & 1,6 & 1,6 \\
\hline $\begin{array}{l}\text { Sal comum } \\
\text { Salt }\end{array}$ & 0,9 & 0,9 & 0,9 & 0,9 \\
\hline $\begin{array}{l}\text { Vitamina } \\
\text { Vitamin }\end{array}$ & 0,3 & 0,3 & 0,3 & 0,3 \\
\hline $\begin{array}{l}\text { Sulfato de amônia } \\
\text { Ammonium sulphate }\end{array}$ & 0,3 & 0,3 & 0,3 & 0,3 \\
\hline $\begin{array}{l}\text { Uréia } \\
\text { Urea }\end{array}$ & 3,0 & 3,0 & 3,0 & 3,0 \\
\hline TOTAL & 100 & 100 & 100 & 100 \\
\hline
\end{tabular}

${ }^{1}$ FCC: farelo de castanha de caju (CNM: cashew nuts meal).

Tabela 2 - Composição química do feno de capim-elefante, do farelo de castanha de caju (FCC) e dos concentrados utilizados no experimento

Table 2 - Chemical composition of elephantgrass hay, of cashew nuts meal (CNM) and concentrates used in the experiment

\begin{tabular}{|c|c|c|c|c|c|c|}
\hline $\begin{array}{l}\text { Parâmetros } \\
\text { Parameters }\end{array}$ & $\begin{array}{l}\mathrm{FCC} \\
C N M\end{array}$ & $\begin{array}{l}0 \% \mathrm{FCC} \\
0 \% C N M\end{array}$ & $\begin{array}{l}12 \% \mathrm{FCC} \\
12 \% \mathrm{CNM}\end{array}$ & $\begin{array}{l}24 \% \mathrm{FCC} \\
24 \% C N M\end{array}$ & $\begin{array}{l}36 \% \mathrm{FCC} \\
36 \% C N M\end{array}$ & $\begin{array}{l}\text { Feno } \\
\text { Hay }\end{array}$ \\
\hline $\begin{array}{l}\text { Matéria seca } \\
\text { Dry matter }\end{array}$ & 91,0 & 85,8 & 82,0 & 83,2 & 84,5 & 84,5 \\
\hline $\begin{array}{l}\text { Proteína bruta } \\
\text { Crude protein }\end{array}$ & 22,1 & 30,1 & 31,3 & 30,8 & 30,3 & 4,5 \\
\hline $\begin{array}{l}\text { Extrato etéreo } \\
\text { Ether extract }\end{array}$ & 35,8 & 3,8 & 9,5 & 14,0 & 20,0 & 2,3 \\
\hline $\begin{array}{l}\text { Fibra detergente neutro } \\
\text { Neutral detergent fiber }\end{array}$ & 18,8 & 10,0 & 10,1 & 10,0 & 10,4 & 78,3 \\
\hline $\begin{array}{l}\text { Cinzas } \\
\text { Ashes }\end{array}$ & 6,9 & 5,0 & 5,8 & 6,4 & 6,3 & 12,7 \\
\hline
\end{tabular}

com 14 dias de adaptação e 42 dias de coleta de dados. O período destinado à coleta de dados foi subdividido em três períodos de 14 dias cada. Durante o período experimental, foram realizadas pesagens periódicas dos animais a cada 14 dias. Semanalmente, foram coletadas amostras das sobras, do feno e das rações concentradas. Nas amostras coletadas foram feitas análises dos teores de MS, PB, EE, FDN e cinzas no laboratório de Nutrição animal do Departamento de Zootecnia da Universidade Federal do
Ceará, segundo a metodologia descrita por Silva (1990).

Foram avaliados os seguintes parâmetros: consumos de MS, PB, FDN e EE, expressos em g/animal/dia, g/UTM $\left(\mathrm{PV}^{0,75}\right)$ e \%PV, ganho de peso e conversão alimentar.

Para comparação das dietas, foi utilizado o teste de média (Duncan), bem como estudo de regressão para os níveis de adição de farelo de castanha de caju na dieta. As análises foram realizadas utilizando-se o programa SAS (Statystical Analyses System). 
Tabela 3 - Composição químico-bromatológica das dietas totais utilizadas no experimento Table 3 - Chemical composition of total diets used in the experiment

\begin{tabular}{|c|c|c|c|c|}
\hline $\begin{array}{l}\text { Parâmetros } \\
\text { Parameters }\end{array}$ & $\begin{array}{c}0 \% \mathrm{FCC}^{1} \\
0 \% C N M\end{array}$ & $\begin{array}{l}12 \% \mathrm{FCC} \\
12 \% C N M\end{array}$ & $\begin{array}{l}24 \% \mathrm{FCC} \\
24 \% C N M\end{array}$ & $\begin{array}{l}36 \% \mathrm{FCC} \\
36 \% C N M\end{array}$ \\
\hline $\begin{array}{l}\text { Matéria seca } \\
\text { Dry matter }\end{array}$ & 84,9 & 83,8 & 84,1 & 84,5 \\
\hline $\begin{array}{l}\text { Proteína bruta } \\
\text { Crude protein }\end{array}$ & 12,5 & 12,6 & 12,4 & 12,2 \\
\hline $\begin{array}{l}\text { Extrato etéreo } \\
\text { Ether extract }\end{array}$ & 2,8 & 4,5 & 5,8 & 7,5 \\
\hline $\begin{array}{l}\text { Fibra detergente neutro } \\
\text { Neutral detergent fiber }\end{array}$ & 57,7 & 57,8 & 57,9 & 58,0 \\
\hline $\begin{array}{l}\text { Cinzas } \\
\text { Ashes }\end{array}$ & 10,4 & 10,7 & 10,9 & 10,8 \\
\hline
\end{tabular}

${ }^{1}$ FCC: farelo de castanha de caju (CNM: cashew nuts meal).

\section{Resultados e Discussão}

\section{Consumo de matéria seca}

Os consumos de matéria seca (CMS), expressos em gramas/animal/dia, \%PV e g/UTM, variaram entre 696,42 e 881,$16 ; 2,9133,51$; e 64,44 e 78,51 respectivamente, quando os níveis de inclusão de FCC no concentrado variaram de 0 a $36 \%$ (Tabela 4 ).

Foram encontradas diferenças $(\mathrm{P}<0,05)$ no consumo de MS, quando expresso em g/animal/dia, \%PV e g/UTM, porém não se observou efeito do sexo para tais parâmetros.

O estudo de regressão mostrou efeito linear e negativo no consumo de matéria seca, com a adição de farelo de castanha de caju ao concentrado, quando expresso em g/animal/dia, \%PV e g/UTM. Este resultado está de acordo com os obtidos por Coppock et al. (1985), que observaram diminuição na ingestão de MS com a adição de lipídeos na dieta.

Quando se compararam as médias de consumo de MS, expresso em g/animal/dia, observou-se que apenas a dieta contendo concentrado com $36 \%$ de farelo de castanha de caju foi inferior à dieta testemunha. Este resultado pode ser explicado pelo fato de apenas tal dieta ultrapassar o nível máximo de $6 \%$ de lipídeos na dieta total. Palmquist (1989) destaca que os efeitos negativos dos lipídeos se acentuam a partir de tal nível.

Quando expresso em \%PV e g/UTM, o consumo de MS foi inferior $(\mathrm{P}<0,05)$ para todas as dietas contendo farelo de castanha de caju, em comparação ao concentrado sem FCC.

O consumo de MS, expresso em \% de PV, também apresentou diferenças entre os tratamentos. Observou-se que a ração sem FCC diferiu de todas as demais, apresentando maior consumo. Não houve diferença $(\mathrm{P}>0,05)$ entre os níveis de 12, 24 e 36\% de inclusão de FCC na ração. Entretanto, no estudo de regressão, observa-se diminuição linear no consumo de MS dos animais, à medida que se elevou o nível de FCC na dieta. Foi observada também diferença significativa no consumo de MS, expresso em g/UTM, entre a ração controle $(0 \%)$ e as demais. Este consumo variou de 78,51 a 64,44 g/UTM para as rações com 0 e $36 \%$ de FCC, confirmando a tendência de diminuição no consumo de MS. Estes resultados indicam que pode ter havido alteração no consumo dos animais, em decorrência da utilização de lipídios na dieta, os quais, provavelmente, atuaram sobre a microflora ruminal, modificando a digestibilidade da fibra e, conseqüentemente, o consumo de nutrientes.

\section{Consumo de proteína bruta}

Constam na Tabela 5 os valores de consumo de PB, expressos em g/animal/dia, \% PV e g/UTM, com suas respectivas equações de regressão. Não foi observado efeito de sexo para nenhum dos parâmetros avaliados.

Pelo estudo de comparação de médias, observa-se diferença $(\mathrm{P}<0,05)$ para o consumo de $\mathrm{PB}$ em g/animal/ dia entre a ração controle $(0 \%)$ e a ração contendo $36 \%$ de FCC. Entretanto, o consumo de PB não diferiu entre as rações contendo 12, 24 e 36\% de inclusão de FCC.

$\mathrm{O}$ consumo de $\mathrm{PB}$ expresso em \% $\mathrm{PV}$ apresentou diferença $(\mathrm{P}<0,05)$ entre os níveis de $0 \%$ e os de 12 , 24 e $36 \%$ de inclusão de FCC (Tabela 5). Entre os níveis de 12 e $24 \%$ não houve diferença nos consumos de PB. Observou-se, contudo, que, em relação ao nível de inclusão de $36 \%$ de FCC, houve diminuição $(\mathrm{P}<0,05)$ do consumo de $\mathrm{PB}$ expresso em \%PV.

$\mathrm{O}$ estudo de regressão mostrou que a inclusão de FCC diminuiu linearmente o consumo de PB. Esta 
Tabela 4 - Consumo de matéria seca de ovinos alimentados com dieta contendo diferentes níveis de farelo de castanha de caju (FCC) na ração concentrada e equações de regressão

Table 4 - Intake of dry matter on sheep fed diets with different levels of cashew nuts meal (CNM) on concentrate and regression equations

\begin{tabular}{|c|c|c|c|c|c|}
\hline & \multicolumn{4}{|c|}{$\begin{array}{l}\text { Níveis de inclusão de FCC } \\
\text { Levels of inclusion of CNM }\end{array}$} & \multirow[b]{2}{*}{$\begin{array}{l}\text { Regressão } \\
\text { Regression }\end{array}$} \\
\hline & $0 \%$ & $12 \%$ & $24 \%$ & $36 \%$ & \\
\hline $\begin{array}{l}\text { g/animal/dia } \\
\text { g/animal/day }\end{array}$ & $881,16 a$ & $762,32 \mathrm{ab}$ & $770,16 \mathrm{ab}$ & $696,42 b$ & $(Y)=859,47-4,55 X, r^{2}=0,3513$ \\
\hline $\begin{array}{l}\% \mathrm{PV} \\
\% L W\end{array}$ & $3,51 \mathrm{a}$ & $3,19 b$ & $3,07 \mathrm{~b}$ & $2,91 b$ & $(Y)=3,46-0,01 X, r^{2}=0,5563$ \\
\hline $\begin{array}{l}\text { g/UTM } \\
\text { g/MSU }\end{array}$ & $78,51 \mathrm{a}$ & $70,50 \mathrm{~b}$ & $68,70 \mathrm{~b}$ & $64,44 b$ & $(Y)=77,15-0,37 X, r^{2}=0,55797$ \\
\hline
\end{tabular}

Médias seguidas de letras diferentes na mesma linha, diferem entre si $(P<0,05)$ pelo teste Duncan.

Means, within a row, followed by different letters are different $(P<.05)$ by Duncan test.

Tabela 5 - Consumo de proteína bruta de ovinos alimentados com dieta contendo diferentes níveis de farelo de castanha de caju na ração concentrada e equações de regressão

Table 5 - Intake of crude protein on sheep fed diets with different levels of cashew nuts meal on concentrate and regression equations

\begin{tabular}{|c|c|c|c|c|c|}
\hline & \multicolumn{4}{|c|}{$\begin{array}{l}\text { Níveis de inclusão de FCC } \\
\text { Levels of inclusion of CNM }\end{array}$} & \multirow[b]{2}{*}{$\begin{array}{l}\text { Regressão } \\
\text { Regression }\end{array}$} \\
\hline & $0 \%$ & $12 \%$ & $24 \%$ & $36 \%$ & \\
\hline $\begin{array}{l}\text { g/animal/dia } \\
\text { g/animal/day }\end{array}$ & $155,83 a$ & $134,10 \mathrm{ab}$ & $133,78 \mathrm{ab}$ & $112,83 b$ & $(Y)=153,54-1,08 X, r^{2}=0,5408$ \\
\hline $\begin{array}{l}\% \mathrm{PV} \\
\% L W\end{array}$ & $0,62 \mathrm{a}$ & $0,56 b$ & $0,53 b$ & $0,47 \mathrm{c}$ & $(Y)=0,62-0,004 X, r^{2}=0,7597$ \\
\hline $\begin{array}{l}\mathrm{g} / \mathrm{UTM} \\
\mathrm{g} / \mathrm{MSU}\end{array}$ & $13,83 \mathrm{a}$ & $12,40 \mathrm{~b}$ & $11,93 b$ & $10,44 \mathrm{c}$ & $(Y)=13,79-0,09 X, r^{2}=0,7602$ \\
\hline
\end{tabular}

Médias seguidas de letras diferentes na mesma linha, diferem entre si $(P<0,05)$ pelo teste Duncan.

Means, within a row, followed by different letters are different $(P<.05)$ by Duncan test.

diminuição pode ser explicada pela redução da ingestão de MS, que ocorreu quando se incluiu o farelo de castanha de caju à dieta. Esta tendência foi observada para os consumos expressos em \%PV e g/UTM.

Observa-se que para o consumo em g/animal/dia, a cada $1 \%$ de inclusão de FCC na ração concentrada, o consumo de PB foi reduzido em 1,08 gramas.

Os dados observados no presente trabalho diferem dos encontrados por Villela et al (1996), trabalhando com caroço de algodão, bem como dos de Rabello et al. (1996) e Grummer et al. (1993), testando grão de soja, os quais não encontraram diferenças nos consumos de $\mathrm{PB}$ em animais alimentados com dietas lipídicas.

Não se observaram diferenças $(\mathrm{P}>0,05)$ entre os consumos de PB para os níveis de 12 e $24 \%$ de inclusão do FCC. Entretanto, com o nível de 36\% de FCC na ração, foi observada diferença $(\mathrm{P}<0,05) \mathrm{em}$ comparação às demais dietas testadas. Neste nível, o consumo de PB foi reduzido em $24 \%$, quando compa- rada à dieta com $0 \%$ de inclusão de FCC.

Para o consumo expresso em \% do PV, observou-se decréscimo de $0,004 \%$ para cada $1 \%$ de inclusão de farelo de castanha de caju no concentrado, enquanto para o consumo expresso em g/UTM o decréscimo foi de $0,09 \mathrm{~g}$ para cada $1 \%$ de inclusão de farelo de castanha de caju.

É importante ressaltar que, para todas as dietas, foi observada ingestão diária de $\mathrm{PB}$ inferior à preconizada pelo NRC (1985), o qual recomenda ingestão diária de $167 \mathrm{~g} /$ dia para ovinos com peso vivo de $20 \mathrm{~kg}$.

Consumo de fibra em detergente neutro

Os consumos de fibra em detergente neutro apresentaram valores variando de 442,79 a 561,22 g/animal/dia, de 1,85 a 2,23 para \% de PV e de 40,97 a 49,99 g/UTM, conforme mostrado na Tabela 6. Esses resultados foram semelhantes aos obtidos por Camurça et al. (2002), que observaram valores médios de 515,04 g/ animal/dia, $1,82 \% \mathrm{PV}$ e $41,97 \mathrm{~g} / \mathrm{UTM}$, trabalhando 
com dietas à base de fenos de gramíneas tropicais. Não foi observado efeito de sexo para os parâmetros avaliados.

Foram observadas diferenças $(\mathrm{P}<0,05)$ entre os consumos de FDN para animais alimentados com rações contendo 0 e $36 \%$ de inclusão de FCC. Entretanto, não se observaram diferenças entre os níveis de 0,12 e $24 \%$ de inclusão de FCC, para os valores expressos em g/animal/dia. O estudo de regressão, por sua vez, mostrou diminuição linear no consumo de FDN dos animais alimentados com níveis crescentes de FCC na dieta (Tabela 6).

Os consumos de FDN em \%PV foram superiores aos citados por Van Soest (1994), que sugere consumo entre 0,8 e $1,2 \% \mathrm{PV}$. Todavia, este mesmo autor comenta que esse limite pode ser ultrapassado, quando a dieta apresentar baixa densidade energética. No caso do presente estudo, como o nível de concentrado na dieta foi baixo (30\%), é possível que os animais tenham buscado compensar tal deficiência ingerindo maior volume de alimentos. É importante salientar que teores elevados de FDN na dieta limitam o consumo de MS, porém induzem ao maior consumo de FDN, quando expresso em \%PV. No presente estudo, as dietas com maiores níveis de farelo de castanha apresentaram menor consumo de FDN. Assim, a informação de Van Soest (1994) justifica-se, pois espera-se que dietas contendo maiores níveis de farelo de castanha apresentem maior densidade energética. Dessa forma, as dietas contendo menores níveis de farelo de castanha seriam mais consumidas, na tentativa de se atingir a ingestão ótima de energia.

\section{Consumo de extrato etéreo}

Os consumos de extrato etéreo variaram entre 25,5 e 65 g/animal/dia; 0,10 e $0,27 \%$ do PV e 2,26 e
6,01 g/UTM(Tabela 7). Não foi observado efeito de sexo para nenhum dos parâmetros avaliados.

O consumo de extrato etéreo, expresso em $\mathrm{g} /$ animal/dia, diferiu $(\mathrm{P}<0,05)$ entre todas as rações fornecidas, observando-se aumento linear no consumo, com a inclusão do farelo de castanha de caju. Para os valores expressos em \% PV e g/UTM, observam-se também diferenças entre o consumo dos animais em todos os quatro níveis de inclusão de FCC na dieta.

Este aumento linear do consumo de extrato etéreo é atribuído ao aumento progressivo de lipídeos na dieta total, devido à inclusão do farelo de castanha de caju. Conforme mostrado na Tabela 3, os níveis de lipídeos na dieta total variaram de 2,5 a $7,52 \%$, o que se deve à inclusão do farelo de castanha de caju.

$\mathrm{O}$ estudo de regressão mostrou comportamento linear positivo para o consumo de extrato etéreo, dessa forma, o consumo em $\mathrm{g} / \mathrm{animal} / \mathrm{dia}, \% \mathrm{PV}$ e $\mathrm{g} / \mathrm{UTM}$ é aumentado de 1,09 $\mathrm{g} / \mathrm{animal} / \mathrm{dia} ; 0,004 \% \mathrm{PV}$ e $0,109 \mathrm{~g} / \mathrm{UTM}$ para cada $1 \%$ de inclusão de farelo de castanha de caju, conforme apresentado na Tabela 7. Ganho de peso e conversão alimentar

Os dados referentes ao ganho médio de peso e à conversão alimentar dos animais alimentados com diferentes níveis de inclusão de FCC na dieta estão apresentados na Tabela 8. Não foi observado efeito de sexo sobre o ganho de peso e a conversão alimentar dos animais.

Não foram observadas diferenças entre os ganhos de peso dos animais para os quatro níveis de inclusão de FCC.

Os ganhos de peso diário variaram entre 55,36 e $88,1 \mathrm{~g} / \mathrm{animal} / \mathrm{dia}$, os quais foram inferiores aos encontrados por Oliveira et al (1986), que observaram

Tabela 6 - Consumo de fibra em detergente neutro de ovinos alimentados com dieta contendo diferentes níveis de farelo de castanha de caju (FCC) na ração concentrada e equações de regressão.

Table 6 - Intake of neutral detergent fiber on sheep fed with diets contents different levels of cashew nuts mea (CNM) on concentrate and regression equations

\begin{tabular}{|c|c|c|c|c|c|}
\hline & \multicolumn{4}{|c|}{$\begin{array}{l}\text { Níveis de inclusão de FCC } \\
\text { Levels of inclusion of CNM }\end{array}$} & \multirow[b]{2}{*}{$\begin{array}{c}\text { Regressão } \\
\text { Regression }\end{array}$} \\
\hline & $0 \%$ & $12 \%$ & $24 \%$ & $36 \%$ & \\
\hline $\begin{array}{l}\text { g/animal/dia } \\
\text { g/animal/day }\end{array}$ & $561,22 \mathrm{a}$ & $494,51 \mathrm{ab}$ & $486,67 \mathrm{ab}$ & $442,79 b$ & $(Y)=554,119-4,322 X, r^{2}=0,3848$ \\
\hline $\begin{array}{l}\% \mathrm{PV} \\
\% L W\end{array}$ & $2,23 \mathrm{a}$ & $2,03 b$ & $1,97 b$ & $1,85 b$ & $(Y)=2,2252-0,015 X, r^{2}=0,5955$ \\
\hline $\begin{array}{l}\mathrm{g} / \mathrm{UTM} \\
\mathrm{g} / \mathrm{MSU}\end{array}$ & $49,99 a$ & $44,99 b$ & $44,11 b$ & $40,97 \mathrm{~b}$ & $(Y)=49,672-0,3491 X, r^{2}=0,5859$ \\
\hline
\end{tabular}

Médias seguidas de letras diferentes na mesma linha, diferem entre si $(P<0,05)$ pelo teste Duncan.

Means, within a row, followed by different letters are different $(P<.05)$ by Duncan test.

R. Bras. Zootec., v.32, n.1, p.240-248, 2003 
valores entre 92,6 e 106,2 $\mathrm{g} / \mathrm{dia}$, trabalhando com ovinos Morada Nova alimentados com restolho de milho e feno de mata pasto (Cassia sericea). Entretanto, foram superiores aos encontrados por Lira (1990), que, trabalhando com ovinos e caprinos alimentados com capim-buffel e leucena, observou valores entre 50 e $69,45 \mathrm{~g} /$ dia. Foram superiores também aos dados encontrados por Gurgel et al (1992), alimentando ovinos morada nova com feno de leucena e capimelefante, cujos valores variaram de 27,41 a 34,19 g/dia.

Por outro lado, os ganhos de peso observados no presente trabalho foram inferiores aos encontrados por Oliveira et al. (1986), que, trabalhando com ovinos Santa Inês alimentados com restolho de milho e feno de cunhã (Clitoria ternatea) e feno de mata pasto (Cassia sericea), encontraram valores de 102,1 e 121,8 g/dia. Foram inferiores, também, ao ganho de peso diário (166 g/animal) observado por Garcia et al.
(2000) para ovinos Santa Inês alimentados com dietas contendo casca de café e concentrado.

Trabalhando com cordeiros Santa Inês x Crioula alimentados com feno de cunhã e concentrado, Barros et al (1997) obtiveram ganho de peso de 141,55 g/dia, sendo superior aos encontrados no presente trabalho. Ganhos de peso superiores aos obtidos no presente trabalho também foram observados por Bett et al (1999) e Bueno (2000), que obtiveram ganhos de peso acima de $200 \mathrm{~g} / \mathrm{dia}$, quando avaliaram desempenho de ovinos oriundos de cruzamento industrial (fêmeas Corriedale com machos Ile de France, Suffolk e Bergamácia) e da raça Suffolk, respectivamente.

Vale ressaltar, entretanto, que os autores supracitados trabalharam com machos jovens, com aproximadamente quatro meses de idade e alimentados com dietas que continham acima de $60 \%$ de ração concentrada, diferente do presente trabalho, em

Tabela 7 - Consumo de extrato etéreo de ovinos alimentados com dieta contendo diferentes níveis de farelo de castanha de caju na ração concentrada

Table 7 - Ether extract intake of sheep fed diets with different levels of cashew nuts meal on the concentrate

\begin{tabular}{|c|c|c|c|c|c|}
\hline & \multicolumn{4}{|c|}{$\begin{array}{l}\text { Níveis de inclusão de FCC } \\
\text { Levels of inclusion of CNM }\end{array}$} & \multirow[b]{2}{*}{$\begin{array}{l}\text { Regressão } \\
\text { Regression }\end{array}$} \\
\hline & $0 \%$ & $12 \%$ & $24 \%$ & $36 \%$ & \\
\hline $\begin{array}{l}\text { g/animal/dia } \\
\text { g/animal/day }\end{array}$ & $25,43 a$ & $40,30 \mathrm{~b}$ & $52,06 \mathrm{c}$ & $65,00 \mathrm{~d}$ & $(Y)=26,13+1,09 X, r^{2}=0,9489$ \\
\hline $\begin{array}{l}\% \mathrm{PV} \\
\% L W\end{array}$ & $0,10 \mathrm{a}$ & $0,16 b$ & $0,20 \mathrm{c}$ & $0,27 \mathrm{~d}$ & $(Y)=0,10+0,004 X, r^{2}=0,9558$ \\
\hline $\mathrm{g} / \mathrm{UTM}$ & $2,26 a$ & $3,72 b$ & $4,64 \mathrm{c}$ & $6,01 d$ & $(Y)=2,34+0,10 X, r^{2}=0,9669$ \\
\hline
\end{tabular}

$g / M S U$

Médias seguidas de letras diferentes na mesma linha, diferem entre si $(P<0,05)$ pelo teste Duncan.

Means, within a row, followed by different letters are different $(P<.05)$ by Duncan test.

Tabela 8 - Médias de ganho de peso e conversão alimentar para ovinos alimentados com dietas contendo diferentes níveis de farelo de castanha de caju (FCC)

Table 8 - Weight gain and feed conversion on sheeps fed diets containing different levels of cashew nuts meal (CNM)

\begin{tabular}{|c|c|c|}
\hline $\begin{array}{l}\text { Dietas } \\
\text { Diets }\end{array}$ & $\begin{array}{c}\text { Ganho de peso vivo (g/dia) } \\
\text { Live weight gain (g/day) }\end{array}$ & $\begin{array}{l}\text { Conversão alimentar } \\
\text { Feed conversion }\end{array}$ \\
\hline $\begin{array}{l}0 \% \mathrm{FCC} \\
0 \% C N M\end{array}$ & $88,10^{\mathrm{a}}$ & 10,0 \\
\hline $\begin{array}{l}12 \% \mathrm{FCC} \\
12 \% C N M\end{array}$ & $72,02^{\mathrm{a}}$ & 10,6 \\
\hline $\begin{array}{l}24 \% \mathrm{FCC} \\
24 \% C N M\end{array}$ & $82,14^{\mathrm{a}}$ & 9,4 \\
\hline $\begin{array}{l}36 \% \mathrm{FCC} \\
36 \% C N M\end{array}$ & $55,36^{\mathrm{a}}$ & 12,6 \\
\hline $\begin{array}{l}\text { Média } \\
\text { Average }\end{array}$ & 74,405 & 10,6 \\
\hline
\end{tabular}

Médias seguidas de letras diferentes na mesma linha, diferem entre si $(P<0,05)$ pelo teste Duncan. Means, within a row, followed by different letters are different $(P<.05)$ by Duncan test. 
que se utilizou concentrado em nível de 30\% da MS.

Os ganhos de peso encontrados no presente trabalho estão aquém do esperado, provavelmente devido a fatores ligados à idade e ao peso inicial dos animais, consumo de matéria seca e extrato etéreo. O peso vivo dos animais no início do experimento, em média $26,5 \mathrm{~kg}$, estava bem acima do peso recomendado para confinamento, que é de 15 a $18 \mathrm{~kg}$ (EMBRAPA,1997).

Além do peso elevado para início do confinamento, os animais entraram no confinamento com idade aproximada de 10 meses, sendo recomendado, para confinamento, animais desmamados, com idade de 4 a 6 meses, embora o peso inicial seja o fator mais importante.

Furusho et al. (1997), trabalhando com ovinos Santa Inês de 15,9 kg e idade variando de 110 a 120 dias, encontraram ganho de peso diário acima de $200 \mathrm{~g} /$ dia, confirmando, assim, que para ganhos de peso satisfatórios em confinamento, devem-se utilizar animais mais leves e mais novos que os utilizados no presente trabalho.

Outro fator importante que está diretamente relacionado ao ganho de peso é o consumo de matéria seca. Os baixos valores para ganho de peso devem-se ao baixo consumo de matéria seca, que foi, em média para as quatro dietas, de 777,51 g/animal/dia, ficando abaixo do recomendado (1000 g/animal/dia) para ovinos de $20 \mathrm{~kg}$ de peso vivo com ganhos de $250 \mathrm{~g} / \mathrm{animal} / \mathrm{dia}$ (NRC, 1985).

$O$ baixo consumo de PB também pode ter influenciado os ganhos de peso. A média do consumo de PB para as quatro dietas, $134,1 \mathrm{~g} /$ animal/dia, ficou abaixo do recomendado (167 g/animal/dia) para ovinos de $20 \mathrm{~kg}$ de peso vivo e ganho de $250 \mathrm{~g} /$ animal/dia (NRC, 1985).

É importante salientar que, em função da baixa qualidade do feno $(4,5 \% \mathrm{~PB}$ e $78,8 \% \mathrm{FDN})$, a dieta total provavelmente apresentou baixos níveis de energia. O baixo valor nutritivo do feno, associado ao baixo nível de inclusão de concentrado na dieta $(30 \%)$, provavelmente contribuiu para o baixo desempenho animal observado.

Não foi verificada diferença $(\mathrm{P}>0,05)$ entre machos e fêmeas para parâmetro ganho de peso. Este resultado está de acordo com o encontrado por Siqueira et al. (1984), que também não encontraram diferenças entre sexo, trabalhando com cordeiros machos e fêmeas da raça Ideal e cruzas de Texel $x$ Ideal.

Estes dados confirmam os resultados obtidos por Camurça et al. (2002), que não observaram diferenças no ganho de peso de ovinos Santa Inês machos e fêmeas. Esse autor argumenta que a provável explicação para esse fato seria a limitação no fornecimento de nutrientes pelas dietas fornecidas. Dessa forma, os animais machos não teriam como expressar seu maior potencial de crescimento.

No entanto, Ciríaco (1983), trabalhando com ovinos Morada Nova encontrou, em média, ganho de peso $23,6 \%$ superior para os machos em relação as fêmeas. Pesquisa da EMBRAPA (1997) reportou que o ganho de peso das fêmeas é cerca de $15 \%$ inferior ao dos machos, confirmando os resultados obtidos por Ciríaco (1983).

A conversão alimentar para as dietas estudadas variou de 9,4 a 12,6, não havendo diferença $(\mathrm{P}>0,05)$ entre as mesmas (Tabela 8).

A taxa de conversão alimentar foi superior à obtida por Ciríaco (1983), cujo valor médio para este parâmetro foi de 13,6, ao trabalhar com ovinos machos e fêmeas da raça Morada Nova, variedade branca, com idade entre cinco e seis meses, alimentados com feno de cunhã e capim-elefante. Superior, também, à encontrada por Oliveira et al (1986), que observaram valor para conversão alimentar de 16,1 para ovinos Santa Inês alimentados com feno de cunhã e concentrados.

No entanto, o desempenho em termos de conversão alimentar foi inferior ao encontrado por Barros et al (1997), que encontrou valor médio de 6,4 para conversão alimentar de ovinos mestiços Santa Inês x Crioula, alimentados com feno de cunhã e ração concentrada. Garcia et al. (2000) também encontraram taxa de conversão alimentar de 7,22 para cordeiros Santa Inês alimentados com silagem de capimNapier e concentrado.

Oliveira et al. (1986), trabalhando com ovinos Morada Nova alimentados com feno de mata pasto e concentrado, encontraram taxa de conversão alimentar de 10,3, semelhante, portanto, à encontrada no presente trabalho.

Não houve diferença estatística entre sexo, para a variável conversão alimentar, embora houvesse tendência de melhor resultado para os machos.

Estes valores diferem dos reportados por Garcia et al (2000), trabalhando com ovinos Santa Inês, em que se verificaram diferenças entre sexo para a taxa de conversão, com melhores resultados para os machos.

Resultado semelhante ao reportado por Garcia et al (2000) foi observado por Ciríaco (1983), que encontrou melhores taxas de conversão alimentar para os machos que paras as fêmeas da raça Morada Nova.

R. Bras. Zootec., v.32, n.1, p.240-248, 2003 


\section{Conclusões}

A adição de farelo de castanha de caju em dietas para ovinos pode limitar a ingestão de matéria seca das dietas, portanto, ao ser utilizado, deve-se monitorar o nível de lipídeos da dieta total.

A utilização do farelo de castanha de caju não elevou o ganho de peso diário dos animais, porém mais estudos devem ser feitos, principalmente para se avaliar o valor energético do farelo de castanha de caju e, conseqüentemente, balancear mais adequadamente as dietas.

\section{Literatura Citada}

BARROS, N.N.; CARVALHO, R.B.; ROSSETTI, A.G. Feno de cunhã para acabamento de borregos. In: REUNIÃO ANUAL DA SOCIEDADE BRASILEIRA DE ZOOTECNIA, 34., 1997, 1997, Juiz de Fora. Anais... Juiz de Fora: Sociedade Brasileira de Zootecnia, 1997. p.382-385.

BETT, V.; SANTOS, G.T.; AROEIRA, L.J.M. et al. Desempenho e digestibilidade in vivo de cordeiros alimentados com dietas contendo canola em grão integral em diferentes formas. Revista Brasileira de Zootecnia, v.28, n.4, p.808-815, 1999.

BUENO, M.S.; CUNHA, E.A.; SANTOS, L.E. et al. Características de carcaça de cordeiros suffolk abatidos em diferentes idades. Revista Brasileira de Zootecnia, v.29, n.6, p.1803-1810, 2000.

CAMURÇA, D.A. NEIVA, J.N.M., PIMENTEL, J.C.M. et al. Desempenho produtivo de ovinos alimentados com dietas à base de feno de gramíneas tropicais. Revista Brasileira de Zootecnia, v.31 n.5, p.2113-2122, 2002.

CARVALHO, F.F.R.C.; FERREIRA, J.Q.; CONCEIÇÃO, J.R.V. Uso da casca de café na alimentação de ovinos em crescimento. In: REUNIÃO ANUAL DA SOCIEDADE BRASILEIRA DE ZOOTECNIA, 32., 1995, Brasília. Anais... Brasília: Sociedade Brasileira de Zootecnia, 1995. p.181-183.

CHILLIARD, Y. Dietary fat and adipose tissue metabolism in ruminants, pigs and rodents: review. Journal of Dairy Science, v.76, p.3897-3931, 1992.

CIRÍACO, A.L.T. Utilização de feno de cunhã (Clitoria ternatea L.) e esterco de galinha no acabamento de cordeiros da raça Morada Nova, variedade branca, para abate. Fortaleza: Universidade Federal do Ceará, 1983.33p. Dissertação(Mestrado em Zootecnia) - Universidade Federal do Ceará, 1983.

COPPOCK, C.E.; WEST, J.W.; MOYA, J.R. et al. Effects of amount of whole cottonssed on intake, digestibility and physiological responses of dairy cows. Journal of Dairy Science, v.68, n.9 p.2248-2258, 1985.

EMPRESA BRASILEIRA DE PESQUISA E AGROPECUÁRIA - EMBRAPA. Avaliação econômica e produtiva de dois sistemas de produção de ovinos de corte utilizando cruzamentos, em Sobral (CE). Fortaleza, 1993. 35p. (Circular Técnica, 3)

EMPRESA BRASILEIRA DE PESQUISA E AGROPECUÁRIA - EMBRAPA. Tabela de composição química e valores energéticos de alimentos para suínos e aves. 3.ed. Concórdia, 1991.28p. (Circular Técnica, 19)

EMPRESA BRASILEIRA DE PESQUISA E AGROPECUÁRIA - EMBRAPA. Terminação de borregos em confinamento no Nordeste do Brasil. Sobral, 1997. 24p. (Circular Técnica, 12)
EMERY, R.S.; HERDT, T.H. Lipid nutrition. The Veterinary Clinics of North America, v.7, p.341-352, 1991.

FURUSHO, I.F.; PÉREZ, J.R.O.; LIMA, G.F.C. et al. Desempenho de cordeiros Santa Inês, terminados em confinamento, com dieta contendo pedúnculo de caju. In: REUNIÃO ANUAL DA SOCIEDADE BRASILEIRA DE ZOOTECNIA, 34 ., 1997, Juiz de Fora.Anais... Juiz de Fora: Sociedade Brasileira de Zootecnia, 1997. p.385-387.

GARCIA, I.F.F.; PEREZ, J.R.O.; TEIXEIRA, J.C. et al. Desempenho de cordeiros Texel x Bergamácia, Texel x Santa Inês e Santa Inês puros, terminados em confinamento, alimentados com casca de café como parte da dieta. Revista Brasileira de Zootecnia, v.29, n.2, p.564-72, 2000.

GRUMMER, R.R.; LUCK, M.L.; BARMORE, I.A. Rumen fermentation and lactation performance of cows fed roasted soybeans and tallow. Journal of Dairy Science, v.76, n.9, p.2674-2681, 1993.

GURGEL, M.A.; SOUZA, A.A.; LIMA, F.A.M. Avaliação do feno de leucena no crescimento de cordeiros morada nova em confinamento. Pesquisa Agropecuária Brasileira, v.27, n.11, p.1519-1526, 1992.

LIRA, R.C. Efeito da substituição do capim buffel (Cenchrus ciliaris L.) pela leucena (Leucaena leucocephala LAM. DE WIT.), na composição química e digestibilidade avaliada em ovinos e caprinos sob confinamento. Recife: Universidade Federal Rural de Pernambuco, 1990. 112p. Dissertação (Mestrado em Zootecnia) - Universidade Federal Rural de Pernambuco, 1990.

NATIONAL RESEARCH COUNCIL - NRC. Nutrient requirements of sheep. 6.ed. Washington, D.C.: National Academy of Science, 1985. 99p.

OLIVEIRA, E.R.; BARROS, N.N.; ROBB, T.W. et al. Substituição da torta de algodão por feno de leguminosas em rações baseadas em restolho da cultura do milho para ovinos em confinamento. Pesquisa Agropecuária Brasileira, v.21, n.5, p.555-564, 1986.

PALMQUIST, D.L. Influence of source and amount of dietary fat on digestibility in lactating cows. Journal of Dairy Science, v.74, p.1354-1360, 1991.

PALMQUIST, D.L. Suplementação de lipídeos para vacas em lactação. In: SIMPÓSIO SOBRE PRODUÇÃO ANIMAL, 1989, Piracicaba. Anais... Piracicaba: Fundação de Estudos Agrários Luiz de Queiroz, 1989. p.11-26.

PIMENTEL,C.R.M. Castanha se caju: produção e conselho internacional. Fortaleza: EMBRAPA/CNPCA, 1992. p.18.

RABELLO, T.G.; VALADARES FILHO, S.C.; SILVA, J.F.C. et al. Grão de soja moído na alimentação de vacas em lactação. III - Eficiência microbiana, amônia e pH. Revista Brasileira de Zootecnia, v.25, n.2, p.271-280, 1996.

SILVA, D.J. Análises de alimentos: métodos químicos e biológicos. Viçosa, MG, Universidade Federal de Viçosa, 1990. 165p.

SIQUEIRA, E.R.; OSÓRIO, J.C.S.; GUERREIRO, J.L.V. et al. Desempenho de cordeiros machos e fêmeas da raça ideal e cruzas Texel x Ideal, criados em pastagem nativa. Pesquisa Agropecuária Brasileira, v.19, n.12, p.1523-1528, 1984.

Van SOEST, P.J. Nutritional ecology of the ruminant. Washington: Cornell University Press, 1994. 476p.

VILLELA, S.D.J.; VALADARES FILHO, S.C.; SILVA, J.F.C. et al. Caroço de algodão para vacas leiteiras. I - Consumo de nutrientes, produção e composição do leite. Revista da Sociedade Brasileira de Zootecnia, v.25, n.2, p.299-308, 1996.

Recebido em: 01/10/01 Aceito em: 18/09/02

R. Bras. Zootec., v.32, n.1, p.240-248, 2003 